\title{
Observations on the State of NASA's GN\&C Engineering Discipline: Results of an Independent Non-Advocate Study
}

\author{
Gerald J. Pawlikowski ${ }^{1}$ \\ - Harlan Brown \& Company (Brown) \\ Cornelius J. Dennehy ${ }^{2}$ \\ NASA Engineering \& Safety Center (NESC)
}

\begin{abstract}
The NASA Technical Fellows periodically conduct State-of-the-Discipline assessments. The GN\&C Technical Fellow contracted Harlan Brown \& Company in 2007 and 2009 to conduct independent, third party studies to gain unbiased insight and understanding into the attitudes and beliefs of NASA's GN\&C Community of Practice (CoP). The paper first outlines the background, objectives and methodology of the studies. The paper then summarizes key study results of the 2007 baseline study, as well as the 2009 update. The update was then used to track and monitor perceptions, identify performance trends, identify areas where further improvement needs to be made in NASA's GN\&C discipline. It also generated feedback on the recently developed GN\&C CoP online knowledge capture and learning site.
\end{abstract}

$\begin{array}{ll}\text { CoP } & \text { Community of Practice } \\ \text { CxP } & =\text { Constellation Program } \\ \text { GN\&C } & =\text { Guidance, Nàvigation, and Control } \\ \text { GSFC } & =\text { Goddard Space Flight Center } \\ \text { JPL } & =\text { Jet Propulsion Laboratory } \\ \text { JSC } & =\text { Johnson Space Center } \\ \text { LaRC } & =\text { Langley Research Center } \\ \text { LAS } & =\text { Launch Abort System } \\ \text { MSFC } & =\text { Marshall Space Flight Center } \\ \text { NASA } & =\text { National Aeronautics and Space Administration } \\ \text { NESC } & =\text { NASA Engineering and Safety Center } \\ \text { SoD } & =\text { State-of-the-Discipline } \\ \text { TDT } & =\text { Technical Discipline Team }\end{array}$

\section{Introduction}

The primary purpose of this paper is to document key results, analysis, and conclusions from a GN\&C discipline assessment study using data gathered by Harlan Brown \& Company (Brown) for the NASA Engineering \& Safety Center (NESC) in July and August 2009. This 2009 study was an update to the first-ever study of the GN\&C CoP produced in 2007, also conducted by Brown. NESC originally enlisted the support of Brown in 2007 to perform an objective, third party assessment of the GN\&C discipline at NASA. The assessment was a survey of both GN\&C NASA people and GN\&C experts

\footnotetext{
'Senior Project Manager, Harlan Brown \& Company, 35 Mellowbrook Drive, Sinking Spring, PA 19608, USA, 610-678-6200,

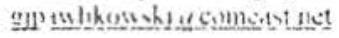

"NASA Technical Fellow for GN\&C, NASA Goddard Space Flight Center, Mail Code 590, Greenbelt, MD 20711, USA, 240-687.

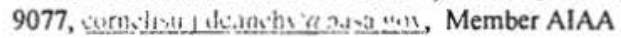


outside of NASA at industry and academia. This 2009 study was aimed at providing NESC and NASA with a tool to monitor and track results from the 2007 study. Both studies focused on developing perceptions of the relative strength of GN\&C as an engineering discipline across NASA. This paper explores how perceptions varied among NASA contacts at NASA HQ, across several NASA centers, as well as at industry, academia and consultants. The perceptions of the contacts on the performance trends, strengths and weaknesses of NASA's GN\&C discipline addressed six specific subdiscipline areas: workforce, analytical methods and tools, developmental testbed facilities and engineering laboratories, testing capabilities, collaboration, and technology development.

\section{A. NESC Background}

The NASA Engineering and Safety Center (NESC), established in July 2003 in response to the Columbia accident, provides independent assessment of technical issues for NASA programs and projects. As its fundamental mission the NESC strives to set the example for engineering and technical excellence within NASA. The primary purpose of this independent and objective organization is to increase safety through engineering excellence. NESC relies on an institutionalized "Tiger Team" approach to solving problems. At the core of the NESC is an established knowledge base of technical specialists pulled from the ten NASA Centers and from a group of partner organizations external to the Agency. This group of engineering experts is organized into 15 discipline areas called Technical Discipline Teams (TDTs). TDTs include "ready" experts from across NASA, industry, academia and other government agencies, Fifteen (15) NASA Technical Fellows, based in the NESC organization, are responsible for assembling, maintaining and providing leadership for the TDTs and serve as stewards for their disciplines. The Technical Fellows support of the Office of the Chief Engineer (OCE) and they are an independent resource to the Agency and industry to resolve complex issues in their respective discipline areas. As part of their discipline stewardship role the NASA Technical Fellows periodically perform State-of-the-Discipline (SoD) assessments of their respective engineering disciplines. This SoD assessments are used to inform senior managers and decision makers within both the OCE and the Office of Safety \& Mission Assurance (OSMA) at NASA Headquarters. In the SoD assessments the Technical Fellows summarize their discipline's readiness to support goals \& objectives of each NASA Mission Directorate, identify the primary technical challenges/barriers for their discipline, and provide advocacy recommendations for their discipline. The NESC organizational model along with the role, purpose and experiences of the NESC GN\&C TDT are described in detail in References 1 and 2.

\section{B. Motivation for The Study}

Having previously gathered the views, insights and observations of the GN\&C TDT the NASA Technical Fellow was interested in expanding the collection of such data from a wider cross-section of the NASA GN\&C CoP. The objective study was thus conceived of as an effective way for NESC to gain un-biased insights and understandings into the 
attitudes and beliefs of the GN\&C practitioners, managers and users across NASA, along with a modest number of industry partners as well. It was anticipated that the study results could inform the planning and technical road mapping tasks of the GN\&C TDT. More specifically, the study findings were seen as an effective way to directly provide valuable information on recent successes, discipline trends, technical challenges, and other issues facing their individual disciplines to support the Technical Fellows' update of the GN\&C State-of-the-Discipline. These expectations have been fulfilled.

\section{What Were Key Study Objectives Of The 2009 GN\&C Discipline Assessment?}

The 2009 study was initiated and managed by the NASA Technical Fellow for GN\&C. Prior to interviewing any contacts a standard set of probing interview questions was defined in collaboration with Brown's Senior Project Manager.

These interview questions were formulated with the following strategic objectives in mind for the study:

$>$ Determine what has changed that makes contacts believe differently about the state of NASA's GN\&C discipline in 2009 vs. its state in $2007 ?$

$>$ Determine to what degree do contacts recognize improvements in the GN\&C discipline at NASA? Determine specifically which GN\&C areas have improved?

$>$ Determine what weaknesses or areas for improvement exist within the GN\&C discipline at NASA that still need to be addressed?

$>$ Determine what are NASA's greatest technical challenges in the GN\&C arena?

$>$ Determine how well known and how useful is the relatively new GN\&C Community of Practice website to NASA's GN\&C engineers? 


\section{Who Was Contacted For The 2009 GN\&C Discipline Assessment?}

A total of 51 reports were gathered including 43 NASA and 8 non-NASA reports. For comparison, in the 2007 study, 76 total reports were gathered. The 43 NASA reports were gathered from GSFC (9), JSC (9), JPL (6), LaRC (5), MSFC (4), NASA HQ (3), and other NASA centers (7) including ARC, DFRC, GRC, and KSC. Of the 43 NASA reports 13 were gathered from GN\&C core TDT members. The 8 non-NASA reports were gathered form support contractors, consultants and academia. $60 \%$ of the 2009 contacts were contacted in the 2007 study. CxP sources (63\%) and non-CxP sources (37\%) were contacted.

GN\&C providers ( $71 \%$ of the sample) and GN\&C users (29\%) were contacted in the 2009 study.

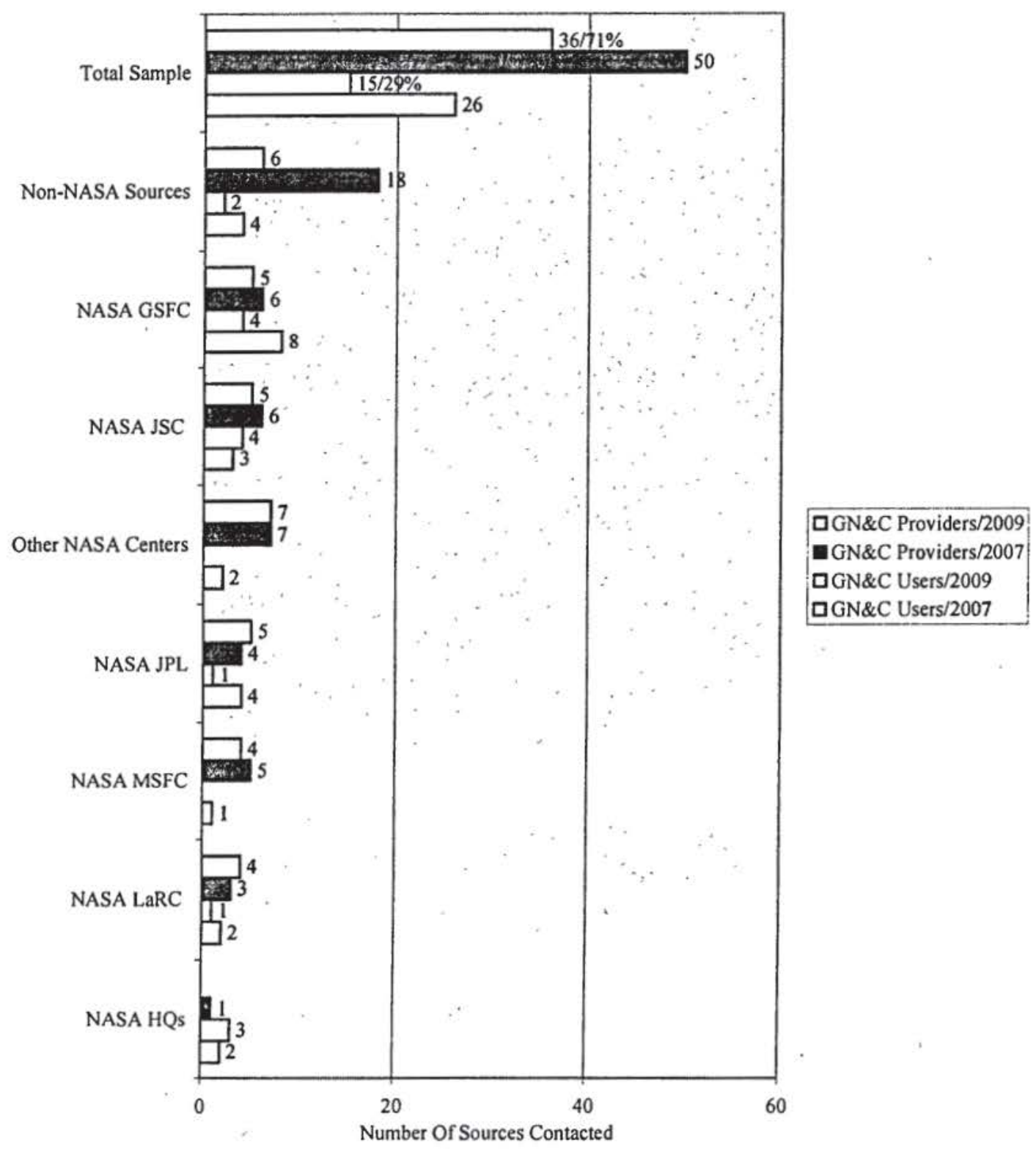

Figure 1. Distribution of study sample in 2009 vs. 2007 studies - by role 
Contacts perspective was NASA-wide ( $25 \%$ of sample) versus their individual NASA Center (75\%) in the 2009 study.

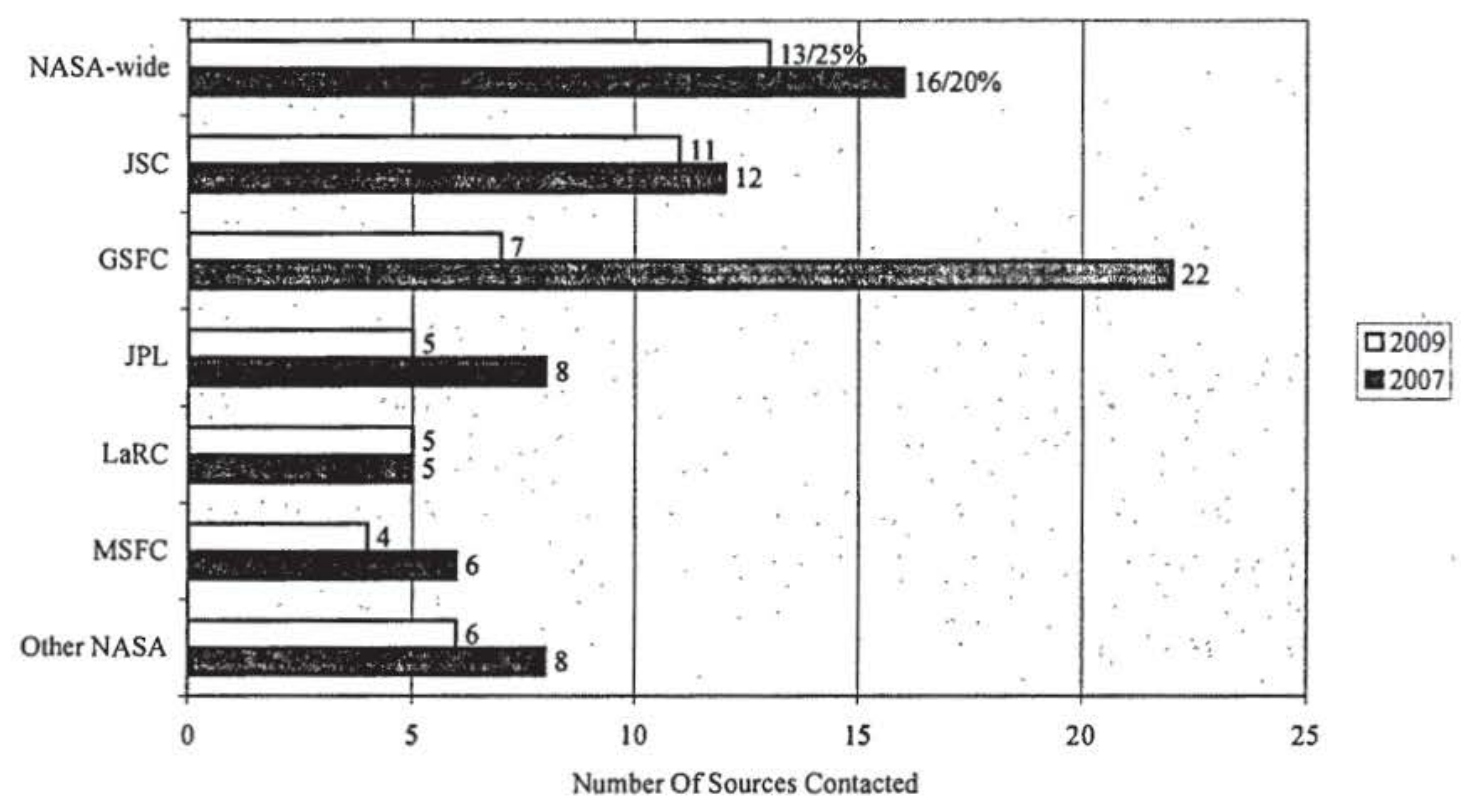

Figure 2. Distribution of study sample in 2009 vs. 2007 studies - by perspective

All study contacts were identified by the NASA GN\&C Technical Fellow as a representative cross-section sample of the GN\&C CoP, including individual technical contributors, flight project leaders, and engineering line organization managers. To preclude the influence of nonobjective biases on the study results there was no reliance on any other data inputs apart from the information gleaned during the individual phone interviews.

\section{E. How was the assessment gathered?}

All information was gathered through in-depth phone interviews with sources. Brown did not rely on the NESC GN\&C Technical Fellow for any study input other than who to contact and what to ask them. The 2007 and 2009 studies were both carried out without attribution; that is without attaching source's name to the reports generated from the telephone interviews. This was done in order to develop as open and honest an assessment as possible from the sources.

Brown has produced a significant amount of customer and supply chain perception analysis assessments for Orbital Sciences, the National Institute of Aerospace, NESC Academy, NESC, and others. Brown's core competency for this study involved reaching and engaging through in-depth phone interviews, a select group of elusive/difficult to normally reach NASA subject matter experts, project managers and senior engineering line managers, as well as non-NASA experts. 


\section{Summary of 2007 Study Findings}

NESC conducted its first independent State-of-the-Discipline assessment on GN\&C within NASA in 2007. The study represented a snapshot of opinion gathered in August-October 2007.

\section{A. Sources Key Expectations Of NASA's GN\&C Discipline}

Brown first established sources opinion of what is most expected and valued from NASA's GN\&C discipline. GN\&C providers, such as design engineers and GN\&C branch heads, identified what they believe is most valued of them. GN\&C users, such as chief engineers and program people, identified expectations in supporting their areas and NASA's goals in GN\&C. Expectations were identified by NASA sources and non-NASA sources.

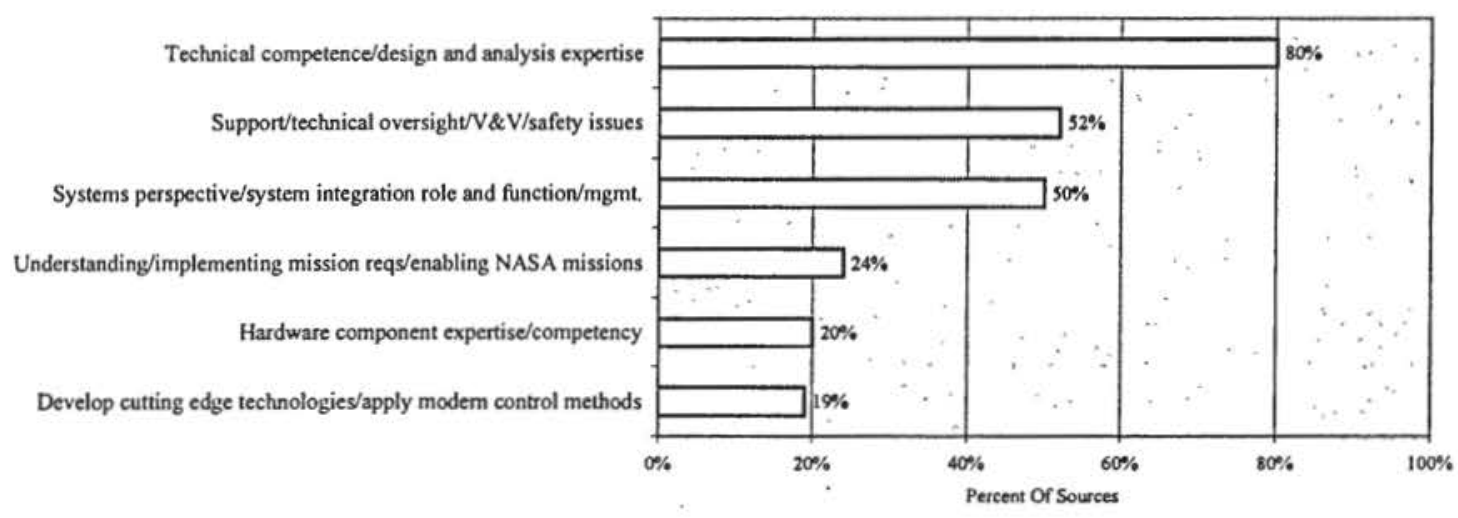

Figure 3. Key expectations of NASA's GN\&C discipline-from NASA sources

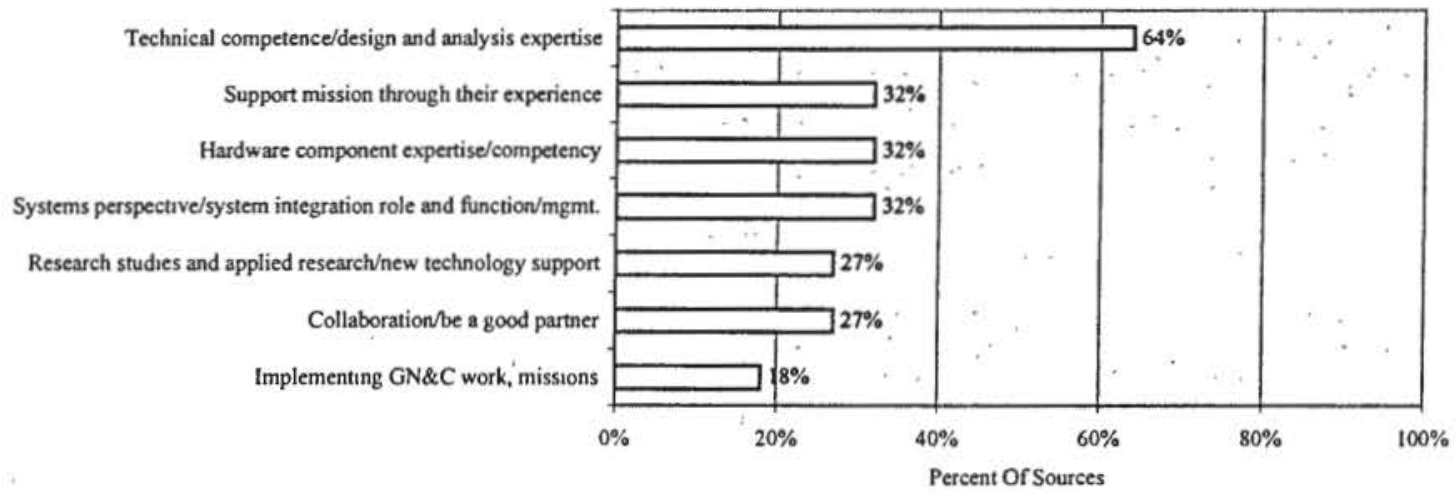

Figure 4. Key expectations of NASA's GN\&C discipline-from non-NASA sources 


\section{B. Relative Strength Of NASA's GN\&C Capabilities in 2007}

A major aspect of assessing the state of the GN\&C discipline was to quantify people's opinion with regard to specific NASA GN\&C capabilities - workforce competence, simulation and software tools, GN\&C facilities, collaboration and technology development activity. Brown also gathered an 'overall' rating of NASA's GN\&C capabilities, a weighted average that takes all factors into account. The 76 total study sources contacted in 2007, on average, rated NASA's overall GN\&C capabilities at a 3.9 (on a 1-5 scale, with 5= excellent). Analytical methods and tools and GN\&C workforce were rated highest, while technology development and collaboration were rated lowest by study sources.

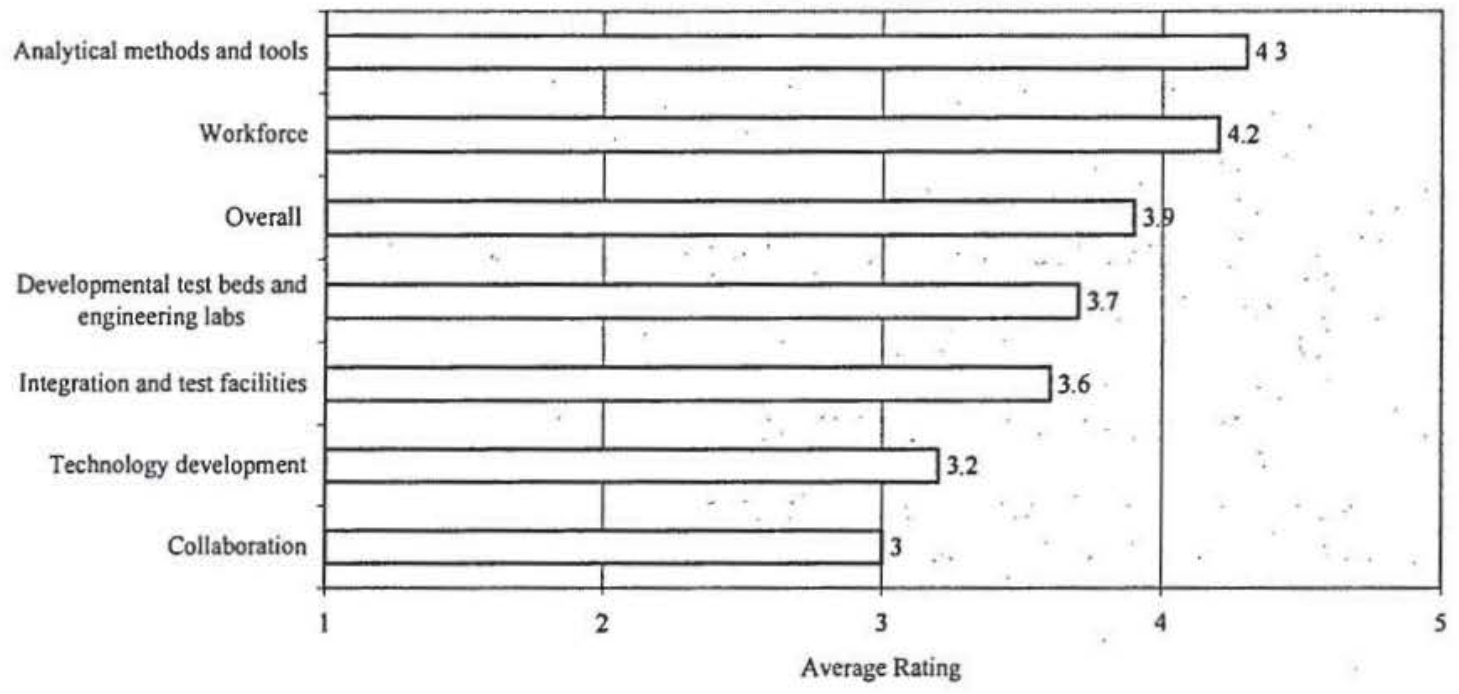

Figure 5. Relative strength of NASA's GN\&C capabilities by area/across all sources ( 1 = poor, 3 = barely acceptable, $5=$ excellent $)$

A fairly narrow band of opinion was expressed in 2007 for the overall rating of NASA GN\&C capabilities across the various sources contacted.

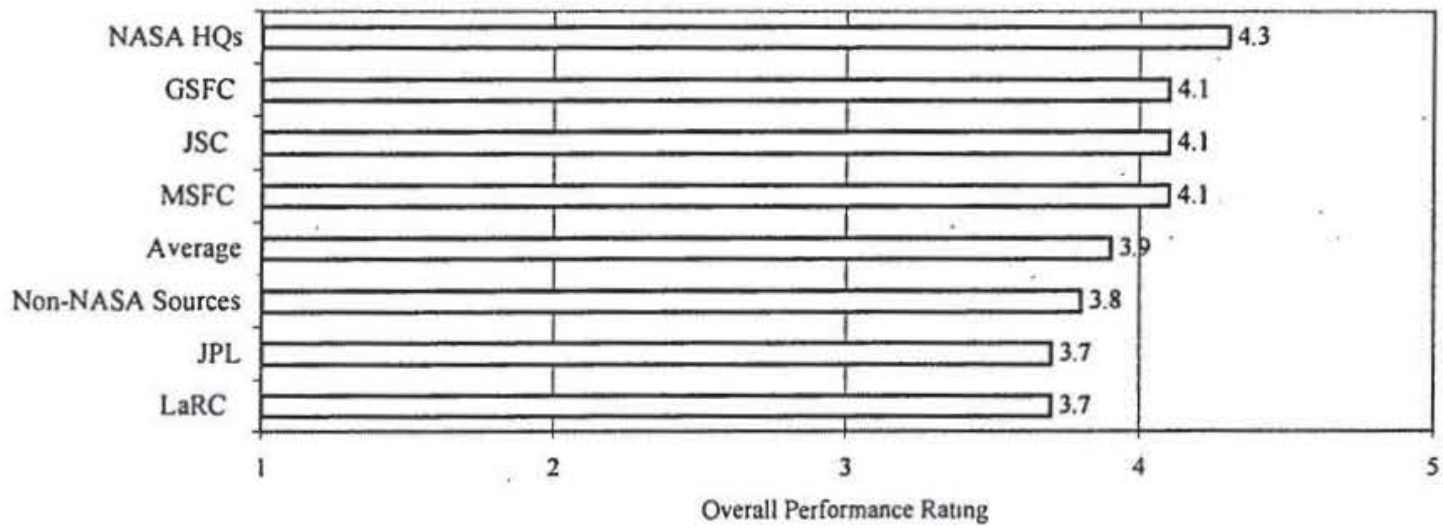

Figure 6. Overall rating of NASA's GN\&C capabilities by source ( 1 = poor, 3 = barely acceptable, $5=$ excellent $)$ 


\section{Relative Strength Of NASA's GN\&C Workforce}

The 2007 study also established a baseline of sources opinion regarding NASA's GN\&C workforce.

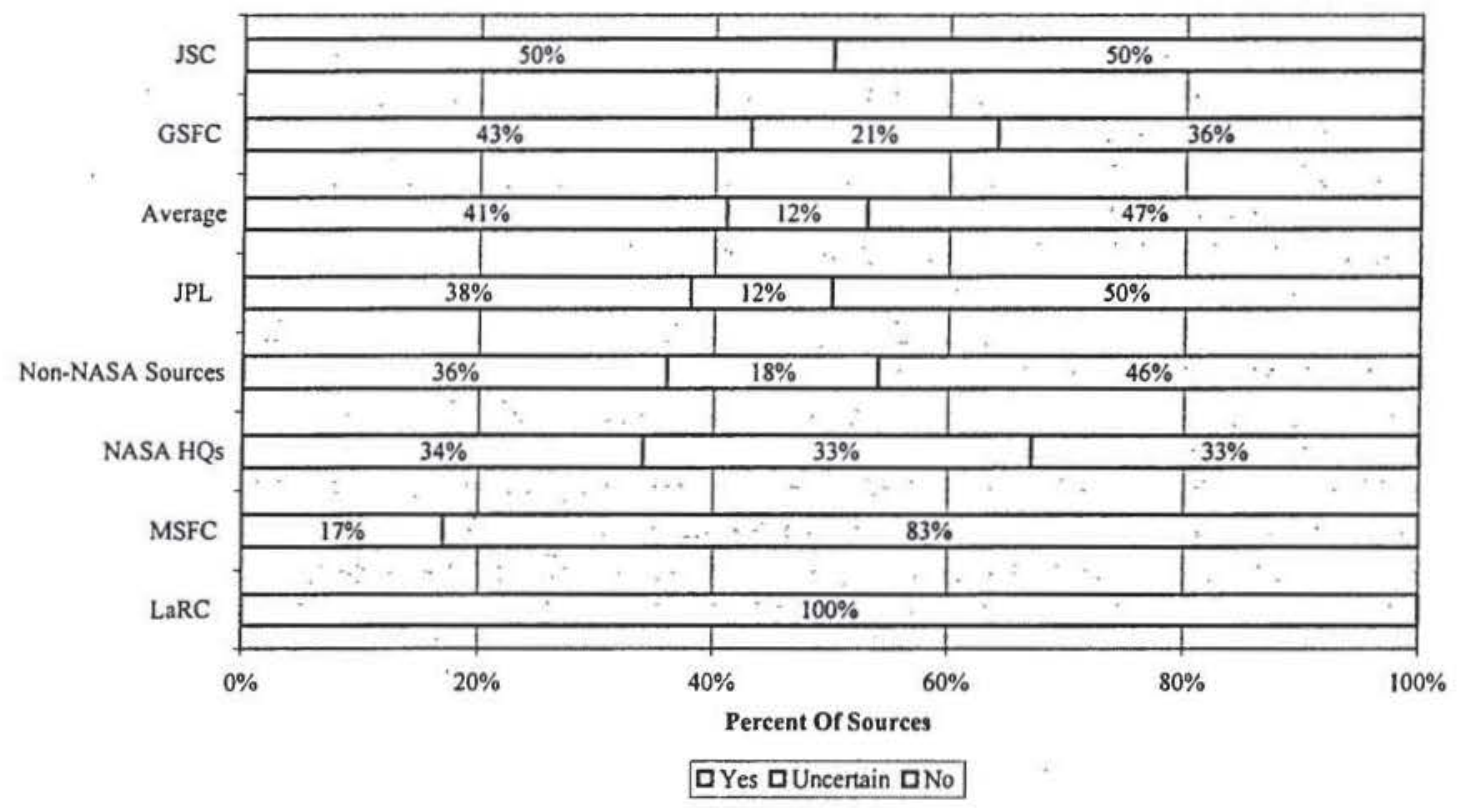

Figure 7. Sources responses to question: Is there a right balance of people (demographics, engineering depth/skill mix) in NASA's GN\&C workforce?

\section{GN\&C Collaboration Across NASA Centers}

The 2007 study also established how well NASA Centers perform GN\&C collaboration (i.e., is there a sharing of experiences, resources, and analytical tools?)

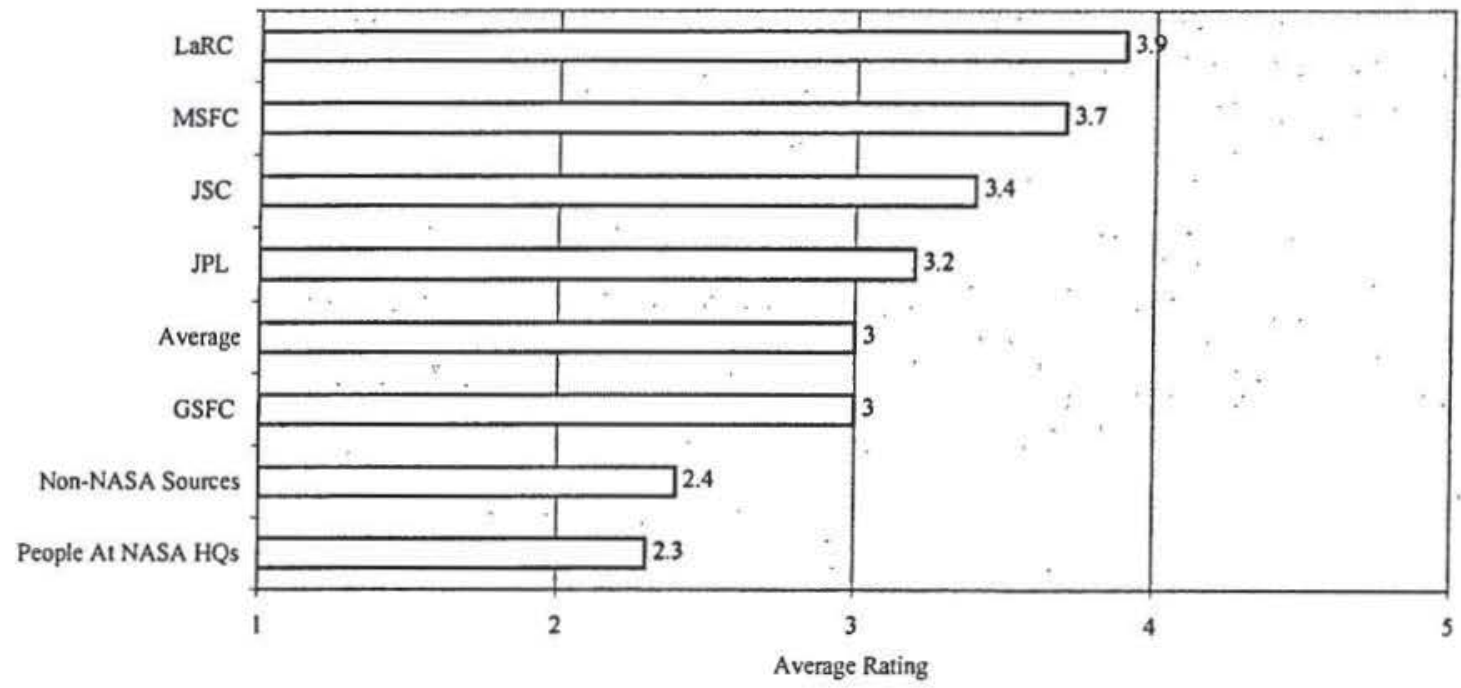

Figure 8. Sources responses to question: How well do NASA field centers perform GN\&C collaboration? $(1=$ poor, $3=$ barely acceptable, $5=$ excellent $)$ 


\section{E. What People Said About The GN\&C Discipline In 2007}

Table 1 provides the most relevant actual quotes from study sources grouped by topic.

\begin{tabular}{l}
\hline NASA's GN\&C Workforce \\
"NASA's GN\&C workforce is now unbalanced. We are top heavy with a high number of people \\
able to retire in 4-5 years if they opt for it. Our workforce quality is very good. However, are we \\
feeding the workforce so it continues to be strong in 5-10 years when we lose high numbers to \\
retirement?" \\
"Workforce experience and competence varies greatly by center. JPL has extremely good engineers \\
whose shear technical competence is very good, but it has weaknesses in being able to build \\
something at an effective cost. GSFC designs more hardware than JPL but is not as complex. JSC \\
has an extremely talented, older and top-heavy workforce, along with younger people with no \\
design experience. LaRC has a younger group that lack experience and perspective." \\
- "NASA has an aging workforce with too small a pool of new young talent being trained. NASA is \\
not thinking ahead about what it is going to do when its aging workforce retires within 10 years." \\
" "NASA has lost a generation of highly skilled GN\&C engineers. NASA has brought in a lot of new \\
hires in the past 8-10 years but they are not experienced enough yet." \\
\hline NASA's GN\&CAnalytical Methods and Tools \\
\hline " "This is strong and improving greatly. GSFC is more willing to invest in this area because it is \\
cheaper to build simulation models and software than it is actual ground test equipment." \\
- "As a result of the Mars missions JPL has had a lot of involvement with entry descent and landing \\
tools and simulations that the rest of the agency doesn't have." \\
" "JSC has a lot of expertise and are being very pro-active in this area. We are driving a lot of this \\
(use/development of simulation tools) agency wide." \\
\hline NASA's GN\&C Facilities \\
\hline "GSFC I\&T facilities are not consistently maintained as well as they should be because of sporadic \\
use. Funding doesn't support facilities to be maintained." \\
"NASA hasn't kept up with satellite integration and test facilities. They have not been kept up to \\
- "GSFC has strong capabilities in these areas, such as its GPS Constellation simulator, and makes \\
them available to outside companies such as ATK. It is important that NASA continues to offer this \\
to outside companies." \\
\hline
\end{tabular}

Table 1. Relevant quotes regarding NASA GN\&C capabilities in 2007 
NASA's GN\&C Collaboration

- "A NASA-wide vision in the GN\&C area is lacking. There is no integrated or planned NASA-wide GN\&C discipline activity but only pockets of task-wise collaboration. We are not involved in an integrated vision in GN\&C that taps into the strengths of each center. There is no clear vision from the top."

- "There is a mix of competition and collaboration between the NASA centers. NASA centers and branches compete for the same work. We have to respect individual's needs to differentiate themselves. A dynamic tension is there and needs to be maintained. It is healthy competition."

- "Successful collaborations have clearly defined roles and responsibilities and significant blocks of work for the NASA centers involved; e.g., on the Mars Science Laboratory between JSC, LaRC and JPL. Collaboration between GSFC and JSC on the Hubble robotic vehicle was a success."

- "Work towards either reducing the competition between centers or leveraging the competition between centers to get something that is truly better and higher capability rather than fighting over the work."

- "Develop discipline specific blue ribbon teams. They could share lessons learned and common practices. They could help form strategies, coordinate workshops, identify technical areas and help identify advanced technology development."

- "The NESC should contribute papers and encourage collaboration models. The NESC needs to continue plugging along in fostering more and more collaboration."

NASA's GN\&C Technology Development

- "Technology development isn't the focus, technology use is the focus. It has to be proven technology at the time it is being used. In areas of relative navigation sensors you are looking at technology development in order to improve and meet relative navigation requirements."

- "Everything is driven by programs. There is no long-term vision for R\&D at NASA. There is too much emphasis on the short term and how is this going to benefit the program, e.g., ISS, vs. NASA long term. ESA is starting to overtake NASA in many ways; e.g., ESA's GPS receiver blows away NASA's GPS receiver."

- "NASA isn't pouring enough money into new technology but only maintaining current technology. NASA is so focused with on-going missions and operations. Little technology development is going on. This is even the case at the NASA research centers. Technology development efforts haven't been coordinated across NASA centers."

Table 1 (Continued). Relevant quotes regarding NASA GN\&C capabilities in 2007 


\section{Summary of 2009 Study Findings}

NESC conducted a follow-up independent State-of-the-Discipline assessment on GN\&C within NASA to keep information gathered in the 2007 study current and up to date. This study represented a snapshot of opinion mostly gathered in July 2009. It is worth noting that the 2009 study coincided with the deliberations of the Review of U.S. Human Space Flight Plans Committee (the "Augustine Panel"). The 2009 study was largely done to monitor and track 2007 study results but also addressed two new areas: 1) NASA's greatest technical challenges in the GN\&C arena, and 2) how well known and useful is the recently developed GN\&C CoP site regarded by NASA's GN\&C engineers.

\section{A. What Has Changed That Makes Contacts Believe Differently About The State Of NASA's GN\&C Discipline In 2009 Vs. 2007?}

\begin{tabular}{|c|c|c|}
\hline Area & 2007 Baseline Study & 2009 Trend \\
\hline $\begin{array}{l}\text { General state of } \\
\text { the GN\&C } \\
\text { discipline }\end{array}$ & $\begin{array}{l}\text { - Study results are mixed, but mostly } \\
\text { positive. } \\
\text { - Overall rating was } 3.9 \\
\text { - NASA's GN\&C discipline is } \\
\text { currently strong, but uncertainty } \\
\text { existed. } \\
\text { - } 2007 \text { performance trend is steady to } \\
\text { slightly improving. } \\
\text { - Uncertainty exists because the GN\&C } \\
\text { discipline is being threatened by } \\
\text { workforce, NASA funding, schedule, } \\
\text { technology development challenges. } \\
\text { - GN\&C users perceive state of } \\
\text { discipline higher (4.1 avg.) than } \\
\text { GN\&C providers (3.9) }\end{array}$ & $\begin{array}{l}\text { - Study results are mixed, but mostly } \\
\text { positive. } \\
\text { - Overall rating remained at } 3.9 \\
\text { - NASA's GN\&C discipline remained } \\
\text { steady or slightly increased across all } \\
\text { areas except technology development. } \\
\text { - } 2009 \text { performance trend is steady to } \\
\text { slightly positive. } \\
\text { - Uncertainty continues to exist; e.g., } \\
\text { NASA funding and outlook for CxP. } \\
\text { - Concern exists regarding GN\&C } \\
\text { facilities and technology development. } \\
\text { - GN\&C users continue to perceive state } \\
\text { of discipline higher (4.1 avg.) than } \\
\text { GN\&C providers (3.9). }\end{array}$ \\
\hline $\begin{array}{l}\text { NASA Center } \\
\text { issues }\end{array}$ & $\begin{array}{l}\text { - NASA HQ, GSFC, JSC, MSFC } \\
\text { expressed above average overall } \\
\text { ratings in } 4.1 \text { to } 4.3 \text { range. } \\
\text { - Non-NASA sources, JPL and LaRC } \\
\text { expressed below average overall } \\
\text { ratings in } 3.7 \text { to } 3.9 \text { range. }\end{array}$ & $\begin{array}{l}\text { - JSC, NASA HQ and GSFC.expressed } \\
\text { high ratings in } 4.1 \text { to } 4.5 \text { range.and } \\
\text { improving trend. } \\
\text { - Non-NASA sources, JPL and LaRC } \\
\text { expressed below average overall ratings } \\
\text { in } 3.5 \text { to } 3.9 \text { range. }\end{array}$ \\
\hline $\begin{array}{l}\text { Workforce } \\
\text { issues }\end{array}$ & $\begin{array}{l}\text { - } 4.2 \text { avg. rating across all sources } \\
\text { Key challenge is the wave of retirees } \\
\text { projected to leave NASA over the } \\
\text { next } 5 \text { to } 10 \text { years. } \\
\text { - Workforce prospects are uncertain } \\
\text { due to past or on-going hiring gaps, } \\
\text { attrition, and GN\&C engineers } \\
\text { migrating to system engineering and } \\
\text { management roles. }\end{array}$ & $\begin{array}{l}\text { - Continued strong at same high rating } \\
\text { - GN\&C workforce perceived to be } \\
\text { improving; e.g., increased experience in } \\
\text { JSC's and GSFC's workforce. } \\
\text { - Workforce concerns/threats continue to } \\
\text { exist with imminent retirement bubble } \\
\text { in two to five ( } 2 \text { to } 5) \text { years. }\end{array}$ \\
\hline
\end{tabular}

Table 2. NASA's GN\&C discipline performance trend in 2009 vs. 2007 


\begin{tabular}{|c|c|c|}
\hline Area & 2007 Baseline Study & 2009 Trend \\
\hline $\begin{array}{l}\text { GN\&C } \\
\text { collaboration } \\
\text { between NASA } \\
\text { Centers. }\end{array}$ & $\begin{array}{l}\text { - GN\&C collaboration considered } \\
\text { inadequate, with a } 3 \text { avg. rating } \\
\text { across all sources } \\
\text { - Rated lowest by NASA HQ ( } 2.3) \text { and } \\
\text { non-NASA ( } 2.4) \text { sources. } \\
\text { - Rated by GSFC at } 3 \text { and JPL at } 3.2 \text {. } \\
\text { - Rated highest by JSC, MFSC and } \\
\text { LaRC in the } 3.4 \text { to } 3.9 \text { range. } \\
\text { - Rated by providers/2.8 and users/3.3. } \\
\text { - Many saw strong collaboration } \\
\text { occurring on CxP, but many also } \\
\text { believed that competition is more } \\
\text { prevalent than cooperation. }\end{array}$ & $\begin{array}{l}\text { - GN\&C collaboration is still mixed but } \\
\text { improved to a } 3.4 \text { level across all } \\
\text { sources mostly due to CxP. } \\
\text { - Key trends from } 2007 \text { to } 2009 \text { : } \\
\text { - JPL: } 3.2 \text { to } 2.7 \\
\text { - LaRC: } 3.9 \text { to } 3.2 \\
\text { - MSFC: } 3.7 \text { to } 3.5 \\
\text { - GSFC: } 3 \text { to } 3.5 \\
\text { - JSC: } 3.4 \text { to } 3.8 \\
\text { - Non-NASA: } 2.4 \text { to } 3.6 \\
\text { - NASA HQ: } 2.3 \text { to } 3.7 \\
\text { - GN\&C providers: } 2.8 \text { to } 3.2 \\
\text { - GN\&C users: } 3.3 \text { to } 3.9\end{array}$ \\
\hline $\begin{array}{l}\text { GN\&C 'hot } \\
\text { button' issues }\end{array}$ & $\begin{array}{l}\text { - Workforce - top heavy, understaffed, } \\
\text { strong competence/experience. } \\
\text { - Component hardware problems, e.g., } \\
\text { reaction wheels and gyros. } \\
\text { - Strong collaboration on Program } \\
\text { Constellation between JSC, MSFC, } \\
\text { LaRC and GRC. } \\
\text { - Strong analytical methods and tools } \\
\text { - CxP challenges }\end{array}$ & $\begin{array}{l}\text { - NASA budget constraints and } \\
\text { uncertainty in NASA's direction and } \\
\text { mission, concerns over CxP outlook. } \\
\text { - GN\&C workforce is more experienced } \\
\text { but threatened with a retirement bubble } \\
\text { in 2-5 years. } \\
\text { - GN\&C COP website is a good start, but } \\
\text { needs to properly represent all NASA } \\
\text { centers including JSC. } \\
\text { - Top technical challenge: Little } \\
\text { investment in next generation GN\&C } \\
\text { component \& system technologies. }\end{array}$ \\
\hline
\end{tabular}

Table 2 (continued). NASA's GN\&C discipline performance trend in 2009 vs. 2007

As the data in Table 2 indicates the relative strength of NASA's GN\&C capabilities appears fairly stable. Little change occurred in sources 1-5 ratings of NASA's GN\&C capabilities between 2007 and 2009, other than significant improvement in collaboration. Analytical methods and tools and workforce continue to be the two highest, stand out, GN\&C performance areas. Technology development is now the lowest GN\&C performance area.

It appears that analytical methods and tools continue to be the highest rated NASA capability because NASA continues to fund, upgrade, and keep current the in-house simulation tools and software as well as the commercially available Matlab® and Simulink® products. Workforce, i.e., technical competence and experience of NASA's GN\&C workforce, had slight improvement due to perceived increased experience of JSC's and GSFC's workforce, recent new hiring and fewer retirements occurred than had been forecast in 2007 to have had a significant impact by 2009. Significant use of support contractors by JSC continues to contribute to stronger GN\&C capabilities there. NASA's overall GN\&C workforce is maturing and more experienced. NASA "greybeards" are not retiring in masses, at least not yet. However, it appears a wave of NASA retirees could occur in the next few years. A slight improvement in testing capabilities may be due to JSC's use of human in the loop testing processes. 
Significant improvement in GN\&C collaboration appears to be due to improved working relationships and more time spent working on CxP since the 2007 study. $63 \%$ of 2009 study sources had some type of involvement with CxP. Increased comfort with the use of collaboration tools such as WebEx® that have become secure is also playing a role. GN\&C collaboration appears that it could easily continue to improve over the next two years with the continued positive impact of NESC's activities, such as the new GN\&C $\mathrm{CoP}$ site, as well as continued growth in tool sharing and cross-Center personnel exchanges.

Technology development activity continues to be regarded as a key area where NASA falls short and is rated so low mainly due to NASA funding trends as of mid-2009.

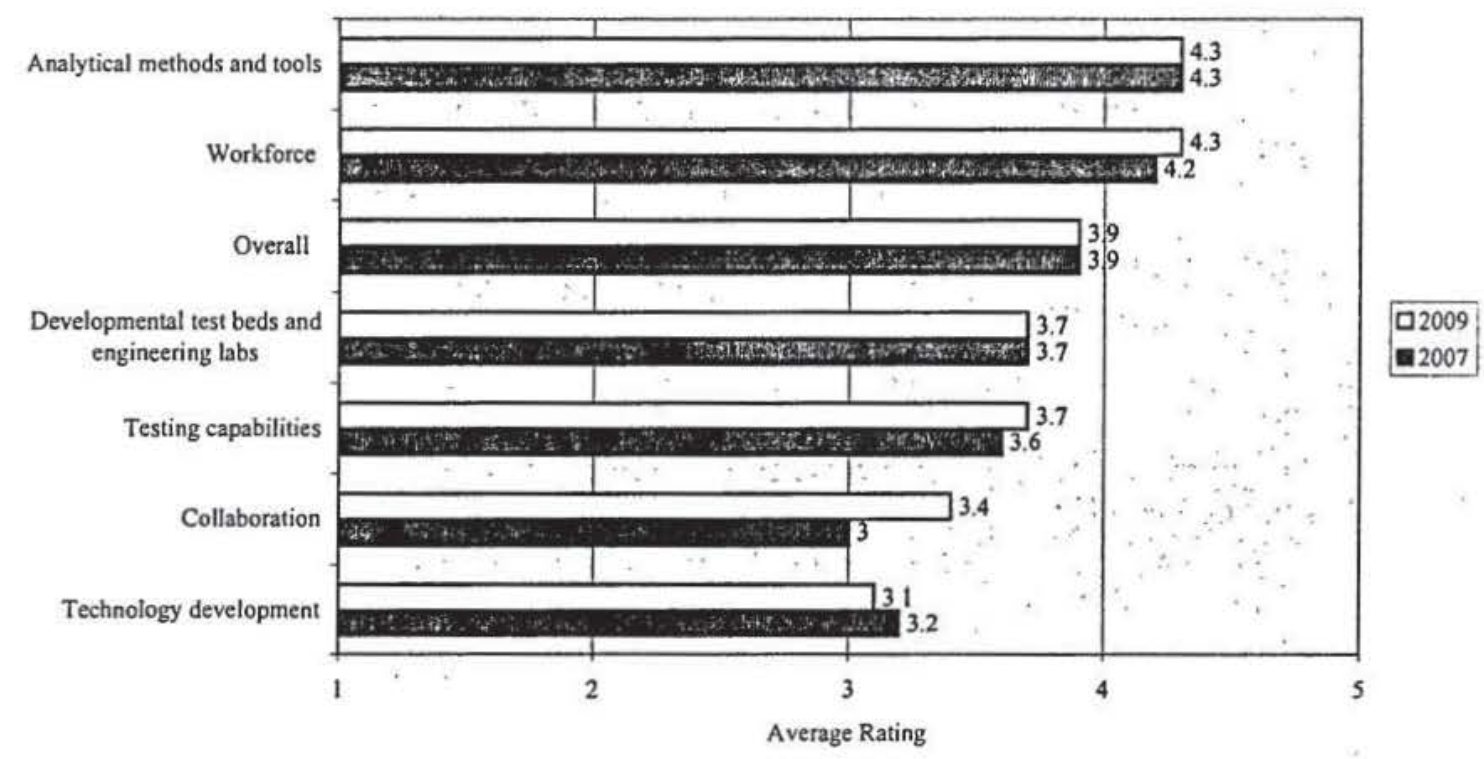

Figure 9. Relative strength of NASA's GN\&C capabilities by area/across all sources for 2009 vs. 2007 ( 1 = poor, 3 = barely acceptable, 5 = excellent) 


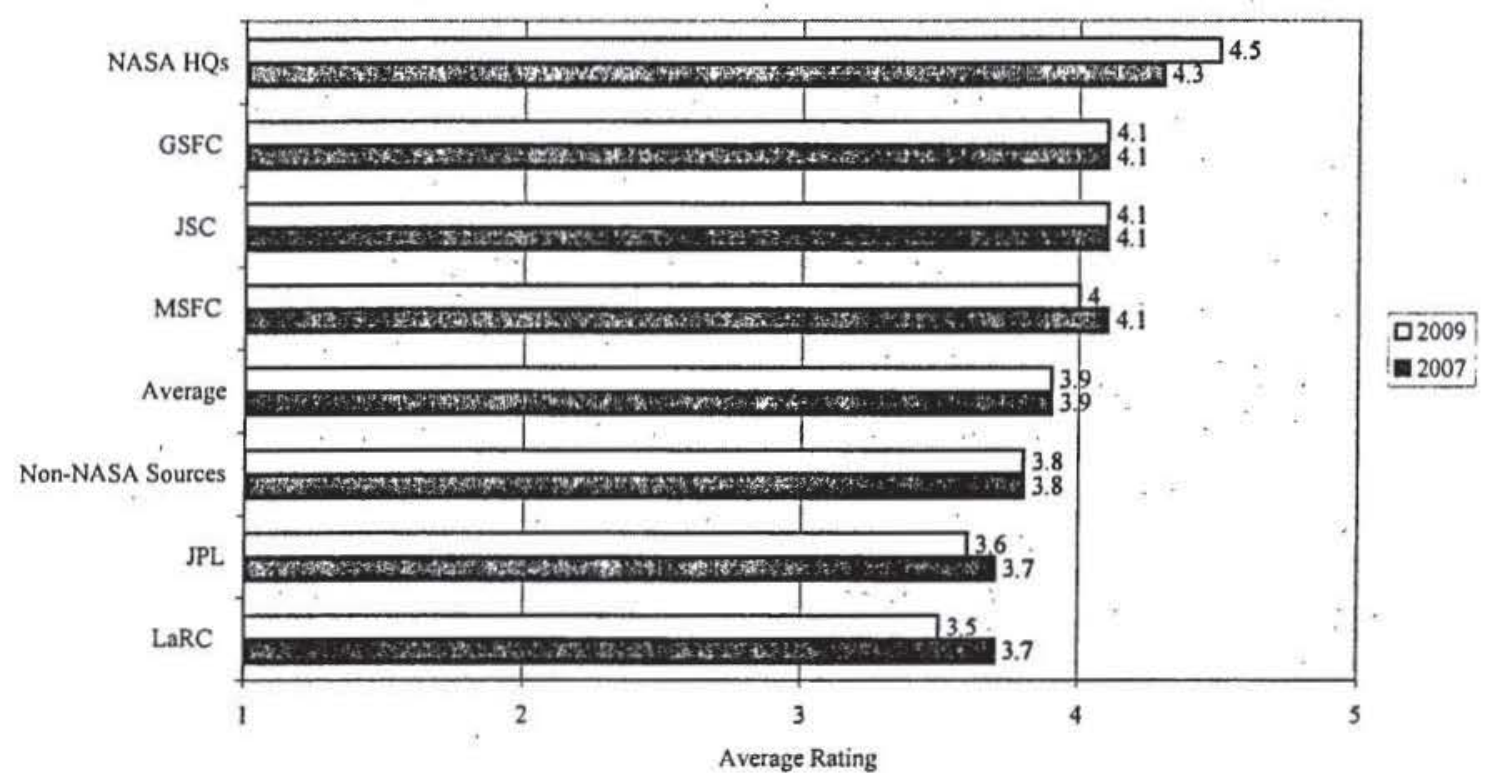

Figure 10. Overall rating of NASA's GN\&C capabilities for 2009 vs. 2007 by source ( 1 = poor, 3 = barely acceptable, $5=$ excellent $)$

These graphs summarize key areas where study sources recognized improvement in the GN\&C discipline at NASA but also weaknesses or areas for improvement that exist within the GN\&C discipline at NASA that still need to be addressed.

It appears the higher rating from NASA HQ, and continued high ratings from GSFC, JSC, and MFSF are directly tied to continued strong workforce competence and improved collaboration on CxP. Rating declines at JPL and LaRC appear most tied to $\mathrm{CxP}$ issues and their people's perception that they have had mixed experience/success with collaboration, as in the case of LaRC, or are unwilling to do it, as in the case of JPL.

GN\&C collaboration was one of the most important issues addressed in this study, i.e., the degree to which it is perceived that NASA Centers share experiences, resources and tools. The numbers indicate sources opinion towards the importance or need for collaboration. They also indicate the degree of collaboration that each NASA Center does or carries out successfully. Higher numbers at GSFC and JSC shows sources there are very happy with collaboration, especially GN\&C users at JSC. Low numbers at LaRC appears to primarily indicate their frustration in collaborating with JSC on $\mathrm{CxP}$. The low number at JPL primarily indicates that sources there believe limited GN\&C collaboration is occurring. It also indicates JPL performs less collaboration than other NASA Centers. These findings at LaRC and JPL could have been impacted by the limited sample size. 


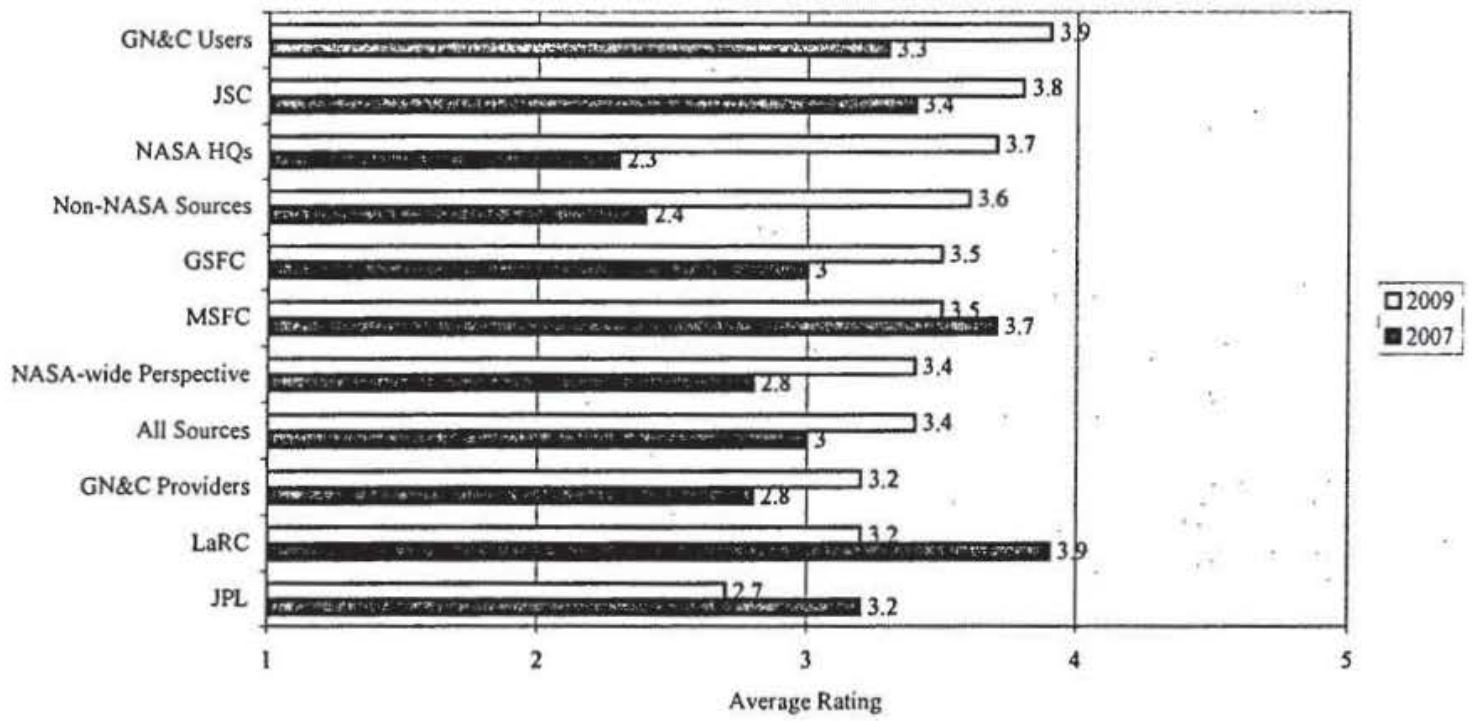

Figure 11. Sources responses to question for 2009 vs. 2007: How well do NASA field centers perform GN\&C collaboration? $(1=$ poor, 3 = barely acceptable, $5=$ excellent $)$

\section{B. What Are NASA's Greatest Technical Challenges In The GN\&C Arena?}

Another area addressed in the 2009 study, which was not addressed in 2007 study, was to assess study sources opinion regarding NASA's technical challenges in GN\&C. The NASA Technical Fellow specified 12 specific sub-discipline technical challenges to be addressed to all study contacts. Brown obtained each source's opinion on a 1-10 scale (with $10=$ highest degree of difficulty) for each technical challenge. Table 12 summarizes the sources' opinion regarding the current degree of difficulty for each technical challenge. 


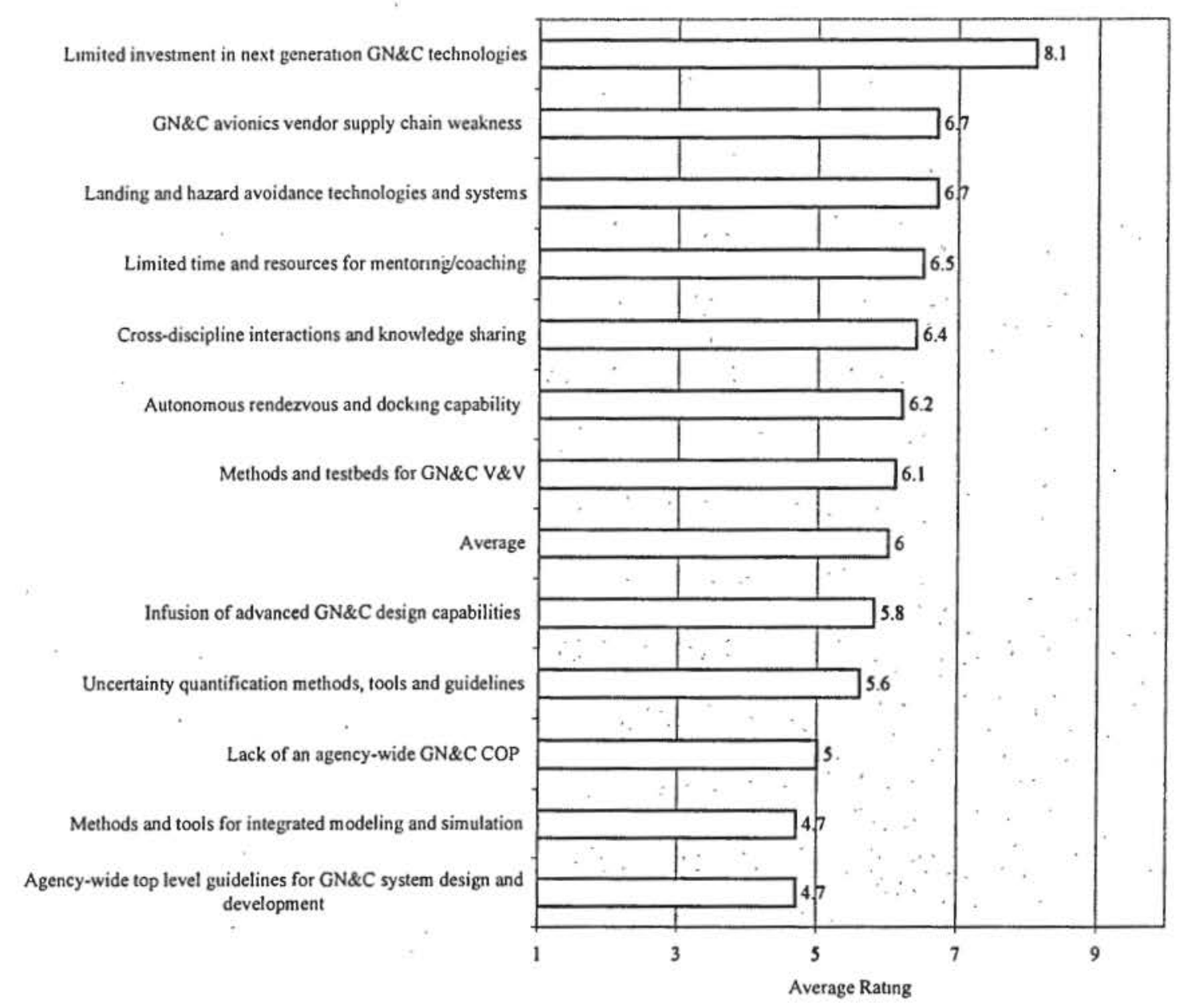

Figure 12. Sources responses to question: What are NASA's greatest technical challenges in GN\&C? across all sources $(1-10$ rating, with $10=$ greatest and $1=$ least significant a challenge)

Sources average ratings for the six project specific technical challenges addressed were: GN\&C for Planetary Entry Descent and Landing (6.8); Orion LAS G\&C (6.7); Robotic Spacecraft GN\&C (6.5); CEV and Altair Lunar Lander Space Vehicle Handling Qualities (5.9); Orion Rendezvous and Docking GN\&C (5.4); and GN\&C for Ares-1/Ares-1X (5.4).

\section{How Well Known and How Useful Is The Relatively New GN\&C CoP Website?}

Another area addressed in the 2009 study, which was not addressed in 2007, was to get feedback from $\mathrm{GN} \& \mathrm{C}$ sources regarding the relatively new $\mathrm{GN} \& \mathrm{C}$ CoP online knowledge capture and learning site. Outside of the 13 core GN\&C TDT members $64 \%$ of sources were not aware of the CoP site until Brown contacted them. It was determined that $85 \%$ of sources had never used the site prior to Brown contacting them. Table 3 summarizes key information Brown developed after bringing all contacts through a demonstration of the CoP site. 


\begin{tabular}{|c|c|}
\hline Issue & \begin{tabular}{|l|} 
Feedback \\
\end{tabular} \\
\hline $\begin{array}{l}\text { What is your } \\
\text { general opinion } \\
\text { of the website? }\end{array}$ & $\begin{array}{l}\text { - Good start ( } 73 \% \text { of sources); very positive }(15 \%) \\
\text { - Weak ( } 12 \%) \text {; needs work, is too busy/difficult to use } \\
\text { - Initial expectations are now low but will grow }\end{array}$ \\
\hline $\begin{array}{l}\text { What are its best } \\
\text { features? }\end{array}$ & $\begin{array}{l}\text { - Document Library (43\%) } \\
\text { - Conferences \& Workshops ( } 31 \%) \\
\text { - Find An Expert (17\%) } \\
\text { - In The News (12\%) } \\
\text { - GN\&C Content Of Interest (12\%) } \\
\text { - FAQs (12\%) } \\
\text { - Reading Room (10\%) } \\
\text { Note: The "Find An Expert" feature came on-line in late July after } 50 \% \\
\text { of the responses had already been gathered. }\end{array}$ \\
\hline $\begin{array}{l}\text { What features } \\
\text { should be added } \\
\text { or improvements } \\
\text { made? }\end{array}$ & $\begin{array}{l}\text { - Broaden it across all NASA centers ( } 77 \%) \text {; it is too GSFC-focused, } \\
\text { there is nothing on JSC, and JPL, LaRC, and MSFC are under- } \\
\text { represented } \\
\text { - Enhance Content Of Interest ( } 41 \%) \text {; e.g., add NASA recs. and } \\
\text { guidelines, standards, standard updates, reqs, and lessons learned } \\
\text { - Make it available to the non-NASA GN\&C community (36\%); e.g., } \\
\text { support contractors and academia. } \\
\text { - Add to the Reading Room ( } 21 \%) \\
\text { - Improve Find An Expert ( } 15 \%) \text {; e.g., broaden it and make it searchable } \\
\text { - Make the Reading Room linkable ( } 11 \%) \\
\text { - Make it easy to contribute to the site }(8 \%) \\
\text { - Add more links, e.g., to NASA HQ library }(8 \%)\end{array}$ \\
\hline $\begin{array}{l}\text { What is the best } \\
\text { way to draw } \\
\text { people to the } \\
\text { website? }\end{array}$ & $\begin{array}{l}\text { - Keep it fresh/current with useful content and data/provide real value } \\
\text { and people will find out about it/it will become 'viral' (79\%) } \\
\text { - Advertise/promote it/targeted emails within the GN\&C } \\
\text { community/link to it/hand out a newsletter at conferences/face to face } \\
\text { meetings (63\%) } \\
\text { - Have NESC core TDT members/top management at each center } \\
\text { inform/meet with their GN\&C colleagues (31\%) } \\
\text { - Provide direct access to documents that people require in order to solve } \\
\text { problems (17\%) } \\
\text { - Personalize it/use graphics and pictures of GN\&C contributions and } \\
\text { GN\&C teams associated with on-going missions/make it live with } \\
\text { blogging ( } 17 \%)\end{array}$ \\
\hline Other comments & $\begin{array}{l}\text { - } 75 \% \text { of non-NASA contacts want access to the CoP site for their } \\
\text { GN\&C people. } \\
\text { - Some believe it needs to be cutback/consolidated to ease upkeep. }\end{array}$ \\
\hline
\end{tabular}

Table 3. Feedback from study sources regarding various GN\&C CoP site issues 


\section{What people said about the GN\&C discipline in 2009}

Table 4 provides the most relevant comments about NASA's GN\&C discipline capabilities, grouped by topic, as obtained by Brown from study sources.

How Expectations Have Changed Since 2007

- "My expectations have certainly become broader since we last spoke. GN\&C's role is critical on Orion in helping me optimize the rest of the system around it and key performance parameters such as mass."

- "Increased expectations now exist in collision avoidance, orbital debris analysis, controlled deorbiting, and inter-satellite interaction. There are growing needs and requirements in these areas."

- "We are moving more towards improving reliability of existing GN\&C capabilities and away from advanced and/or more precise capabilities."

- "We are really looking for earlier requirements definition particularly for launch vehicles to allow initial enveloping of GN\&C requirements so software design work is in parallel."

NASA's GN\&C Workforce

- "NASA's GN\&C workforce continues to improve because of an increasing experience level. JSC's workforce quality has especially improved."

- "GSFC's workforce is technically excellent across the board. A lot of GSFC people are highly recognized in their field."

- "JSC's experience level has continued to improve with our work on Orion. Younger engineers have been getting a lot of experience. Our staffing has increased as well with a good number of cooperative students and new hires."

- "I am concerned GN\&C workforce quality will decline due to a retirement bubble in a few years and a hiring gap. I don't see a lot of new hiring occurring at most NASA centers."

- "NASA has lost some top GN\&C people. A lot of the top GN\&C people are graybeards and will retire soon. I am concerned how much training and mentoring is going on across NASA in attitude determination."

- "GN\&C workforce is declining at some NASA centers because the workforce is old. A retirement bubble will be occurring shortly at MSFC and LaRC. I am less concerned with JPL and JSC in this area."

- "Hiring still isn't steady enough. We need a consistent ability to hire. The GN\&C workforce will decline unless we have the ability to backfill as people retire or leave.".

- "GN\&C workforce has declined and continues to decline because we are not getting the quantity and quality of people that we used to get at GSFC and all of NASA. A retirement bubble is imminent within 2-5 years."

NASA's GN\&C Collaboration

- "Collaboration does matter, but I am not sure how we can get around the distinct cultures and competition that can occur between NASA centers."

- "Collaboration is very strong currently. There is very good cooperation and we work together very well. People are getting to know each other and better understand their roles. The Orion flight dynamics MOD team is the best example of strong collaboration between JSC, LaRC, JPL and ARC."

- "Collaboration between NASA centers is improving. More exchanges are occurring between centers. A means to share secure files has developed between NASA centers and select NASA support contractors through ICE. There has also been increased use of WebEx and its equivalents."

- "NASA is not acting efficiently in terms of collaboration. There is not a lot of automatic collaboration that occurs at NASA in terms of knowledge sharing. Collaboration is forced."

- "Agency wide standards for file sharing should be developed. Webcasts and shared white boards should also be utilized to improve collaboration."

Table 4. Relevant quotes regarding NASA GN\&C capabilities in 2009 
NASA's Technology Development

- "Has improved due to emerging new GN\&C technologies associated with Program Constellation; e.g., navigation sensors and algorithm development for hazard avoidance."

- "Technology development is slightly improving due to ALHAT work, but we do a poor job at achieving technology developments. Sensor and actuator technology development activity is very poor. We don't anticipate technology development needs. We are busy with flight projects and not technology development."

- "I have a long term concern over the lack of sufficient GN\&C hardware in-house development opportunities. JSC has chosen to buy and develop a lot of the GN\&C hardware and software for Orion/CEV on the outside, e.g., through Draper Labs."

- "Continued decreased funding continues to negatively impact this. I see very isolated examples of new technology development; e.g., advanced plasma dynamic thruster advanced propulsion systems - i.e., the Variable Specific Impulse Magnetoplasma Rocket (VASIMR®) system developed by (Franklin Chang-) Diaz."

GN\&C CoP Website In General

- "It's new and looks fine as a good start. I like the look and the feel of it."

- "There is a lot of valuable information on it. It has the potential to be an excellent website."

- "It's an excellent idea. It's a nice start, a good centralized location for the GN\&C COP."

- "It's a really good tool for GN\&C practioners."

Suggested New Features/Improvements To GN\&C CoP Website

- "For a first time user it is difficult to know the place to go to access the website."

- "List on-going missions, the GN\&C team associated with each mission, and what they want to post concerning their missions such as problems they are working on."

- "Personalize it. Have NASA centers contribute a highlight story. Have a different center featured each month. Make it 'the place' for GN\&C information."

"A COP website on GN\&C should be a available to non-NASA people. Industry and academia should be aware of NASA best practices."

The Future Of The GN\&C Discipline (As Viewed In July 2009)

- "With the concern in lack of NASA funding there has been a drop off in the GN\&C discipline. There is inadequate investment occurring in NASA's capabilities. There is uncertainty with CxP depending on the outcome of the Augustine Commission."

Table 4 (Continued). Relevant quotes regarding NASA GN\&C capabilities in 2009 


\section{E. Browns's 2009 Study Conclusions}

After careful consideration and analysis of all the data and other study information Brown identified the following key conclusions from the 2009 study:

The state of NASA's GN\&C discipline has largely remained stable since 2007. The state of the discipline is at least steady if not slightly improved and fairly strong.

Mostly positive perceptions exist due to NASA's strong workforce, analytical methods and tools, GN\&C collaboration and improving GN\&C performance trend out JSC and GSFC.

$>$ Some mixed perception continues to exist since the 2007 study, primarily due to GN\&C workforce concerns for the next five (5) years.

$>$ Mixed perceptions also exist due to uncertainty with regard to NASA funding and the outlook for CxP, poor technology development, concern over GN\&C facilities, some mixed views regarding GN\&C collaboration, and declining GN\&C performance trends out of JPL and LaRC.

$>$ The GN\&C CoP in general is strongest at GSFC, JSC and MSFC. However, it appears that the ties to the GN\&C CoP could be strengthened at JPL and LaRC.

The 2007 and 2009 studies by Brown helped the NASA GN\&C Technical Fellow to not only confirm and validate some of his own perceptions but also to gain new perspectives from colleagues within the $\mathrm{CoP}$ about other aspects of the GN\&C discipline.

The 2007 and 2009 state of the GN\&C discipline assessments also received visibility within NASA. The results of the 2007 Brown study were presented to the GN\&C TDT core members and the NESC Director at LaRC. The 2009 study results were presented to the GN\&C TDT and the NASA Office of the Chief Engineer at NASA Headquarters. Separately a focused discussion on the relevant findings concerning the $\mathrm{CoP}$ online site was held with CoP website design and development team based at JPL.

Study contacts appreciated that NESC did the study in 2007 and expected feedback on the study results. Study contacts appreciated that NESC updated the 2007 study in 2009 and continues to monitor the state of the GN\&C discipline within NASA. Such nonadvocate discipline assessments should have broad application to other engineering discipline Community of Practices across NASA and it is anticipated that other Technical Fellows may perform similar studies. 


\section{F. "Tying it all Together" (NASA Technical Fellow Conclusions)}

So given the results of the 2007 and 209 Brown studies what can one broadly conclude about the state of the GN\&C discipline within NASA? The good news is that the GN\&C discipline at NASA has largely remained stable since 2007. It is mature, healthy, and well poised to meet the challenges of the future. Mostly positive perceptions exist due to NASA's strong workforce, analytical methods and tools, GN\&C collaboration and the improving GN\&C performance trend seen across most NASA Centers. Of particular importance is the fact that several of the most experienced GN\&C engineers within the Agency have not yet retired as was anticipated by many to have occured. These senior engineers and line managers are providing strong mentoring to the youngest generation of the NASA GN\&C engineering staff. However we must acknowledge that mixed perceptions also exist, primarily due to GN\&C workforce concerns for the next 10 years when without doubt the most experienced NASA GN\&C engineers will have retired. Mixed perceptions also exist due to uncertainty with regard to NASA funding and the outlook for CxP, poor technology development, concern over GN\&C facilities, some mixed views regarding the continuation of GN\&C collaborations.

Fortunately, in the Human Spaceflight arena, the Constellation Program has provided multiple challenging learning opportunities for the next generation of GN\&C engineers. Very positive cross-Center collaborations, primarily between JSC, MSFC and LaRC, have occurred during the Orion spacecraft GN\&C system design process, the Ares-1X and Ares-1 launch vehicle flight control system design process and the Orion Launch Abort System (LAS) design process. Likewise having multiple robotic spacecraft under development at JPL and GSFC has provided GN\&C engineers at those Centers outstanding learning and development experiences.

\section{G. The Future for the GN\&C CoP and Some Future Study Considerations}

On February 1, 2010 the President's Budget Request was released. This budget request has significant potential ramifications for NASA, especially at KSC, JSC and MSFC, as it proposes the cancellation of the Constellation Program (CxP) along with the formulation of several new programs that seek to foster a sustainable human space exploration enterprise. In response, NASA has formed multiple study teams to investigate options for implementing these plans to take the Agency in new directions, if and when authorized by Congress. Not to be overlooked is the imminent retirement of the Space Shuttle occurring in parallel with these other dramatic changes at NASA. Among these changes is the move to include the use of commercial industrial partners for crew and cargo delivery to the ISS. Although the Agency's philosophy and approach to exploration will apparently change, NASA's fundamental goal remains the same: to send human explorers into the solar system to stay.

Obviously no one has a crystal ball to predict the future of the GN\&C discipline within NASA as these profound changes unfold. It is however fair to assume that in the next few years the GN\&C discipline within NASA will most likely remain stable and may in fact 
prosper with the investment in the development new technologies. Opportunities for innovative GN\&C system development for robotic spacecraft will likely increase with growing demands for Earth and Space Science spacecraft as well as new Robotic Precursor vehicles. The challenge of designing and developing a new GN\&C system for the planned Orion Emergency Rescue Vehicle is on the horizon as well. There is also high potential for new funding for GN\&C technology development and in-space demonstrations of both Autonomous Rendezvous \& Docking (AR\&D) systems and Autonomous Precision Landing (APL) systems.

A new Flagship Technology Demonstrations Program is currently being planned to demonstrate the key technologies NASA needs to reduce the cost and expand the capability of future space exploration activities. Large scale on-orbit demonstrations of technologies that could be transformational will be performed. The demonstration of Autonomous Rendezvous and Docking (AR\&D) is a primary objective of the Flagship Technology Demonstrations Program. AR\&D is the ability of two spacecraft to rendezvous, operating independently from human controllers and without other back-up, requires advances in sensors, software, and realtime on-orbit positioning and flight control, among other challenges. This GN\&C-based technology is critical to the ultimate success of capabilities such as in-orbit propellant storage and refueling, and complex operations in assembling mission components for challenging destinations.

The Enabling Technology Development and Demonstration (ETDD) Program is also currently being planned to develop and demonstrate prototype systems to feed the Flagship Technology Demonstrations, robotic precursor, and other missions of opportunity. The ETDD Program will develop long-range, critical technologies to provide the foundation for a broad set of NASA's future exploration capabilities. It will also provide infusion paths for promising, game-changing technologies developed by NASA's Space Technology Program. One key question the ETDD Program will attempt to answer is the following: How can we land autonomously, precisely, and safely on a extra-terrestrial surface in uncertain environments? An Autonomous Precision Landing (APL) demonstration will be performed under this new Program to test an integrated GN\&C-based autonomous landing and hazard avoidance system consisting of imaging sensors together with navigation and control algorithms. NASA plans to develop an atmospheric flight experiment to demonstrate an autonomous precision landing and hazard avoidance system on a small lander test bed. NASA would pursue use of this system on a U. S. or international robotic precursor mission to the Moon or other planetary body around 2015 .

This APL work, similar to the AR\&D work, promises to significantly advance NASA's GN\&C capabilities opening up many new crewed and robotic mission applications. This new era in human exploration will challenge the persistence, flexibility, ingenuity and innovation of the GN\&C CoP. Clearly as NASA changes direction over the next few years we must maximize retention of the GN\&C skilled personnel, from within NASA and its Industry partners that can contribute to future technology developments such as AR\&D and APL. 
The development of groundbreaking new GN\&C technologies, including AR\&D, APL and others, will serve to enable exploration of new worlds and increase our understanding of the Earth, our solar system and the universe beyond. The GN\&C CoP will need to be flexible and responsive to the many coming changes. For example, we will be pressed to find new collaborative ways to exploit the International Space Station to increase NASA's return on investment by providing an optimal on-orbit test bed for GN\&C technology research and development. In order to accomplish our future goals we will need cross-Agency GN\&C collaborations to continue and to improve and not suffer with Centers competing against each other under the stresses of moving forward with new NASA direction.

There are other forthcoming fundamental changes to the way NASA has been doing business for over a generation which must be accommodated by the GN\&C workforce. One is the imminent end of the Space Shuttle Program (SSP) in FY11. Another is the proposed Commercial Crew Initiative. These two major changes are inter-related. The closeout of the SSP has the potential to impact the NASA GN\&C workforce, particularly at those Centers that are focused on Human Spaceflight missions. We must guard against any erosion in GN\&C capabilities following the Space Shuttle retirement. The skills of the highly experienced GN\&C hardware and software specialists, who currently provide system integration and sustaining engineering functions for the Space Shuttle, will be critical to NASA's plans for developing the Orion Emergency Rescue Vehicle and for providing Insight/Oversight functions in support of the Commercial Crew Initiative. The Commercial Crew Initiative objectives are to facilitate the development of a U.S. commercial crew space transportation capability with the goal of achieving safe, reliable, and cost effective access to and from LEO and the International Space Station (ISS). Therefore when the plans being formulated now are implemented, if and when authorized by Congress, there will be a stronger reliance by NASA on the commercial providers from industry to develop a safe, reliable space vehicle. An NASA Insight/Oversight approach is currently envisioned that will require a change in the way NASA and industry interact for human spaceflight missions. The goal is for NASA to have in-depth insight of the vehicle design through NASA personnel who are embedded in the contractor's facility while simultaneously maintaining a more traditional higher-level Oversight role of the contractors work. It is reasonable to assume a future demand will be placed on NASA's GN\&C engineers to assume the responsibility for Insight/Oversight roles in support of the Agency's new direction towards utilizing commercial crew services. All these developments will no doubt place a strain on the GN\&C workforce as NASA moves out in all these bold new directions as highlighted above.

With so much change occurring within NASA and new challenges emerging it will be important to monitor and track emerging trends and dynamics of the GN\&C CoP. In light of changing directions and the post-Constellation/post-Space Shuttle NASA working environment it is likely that a third non-advocate study will be performed in mid-to-late 2011 to evaluate the state of the GN\&C discipline, with a special emphasis on understanding $\mathrm{GN} \& \mathrm{C}$ workforce concerns. 


\section{Acknowledgments}

The authors thank the following individuals: the many members of the GN\&C Community of Practice who volunteered to give their time to provide the insights and observations so essential to making this objective study a success; the members of the NESC GN\&C TDT for their unique contributions; the members of the NESC Leadership Team at NASA's Langley Research Center for their support and encouragement in the work of the GN\&C TDT in general and the development of this paper in particular; Harlan Brown and Scott Glubke (GSFC Code 590 Chief Engineer) for their thoughtful review and commentary of this paper.

\section{References}

1. "The NASA Engineering \& Safety Center (NESC) GN\&C Technical Discipline Team (TDT): Its Purpose, Practices and Experiences", C. J, Dennehy, AIAA2007-6332, GN\&C Annual Conference, Hilton Head, SC, August 2007

2.. "Recent Experiences of the NASA Engineering \& Safety Center (NESC) GN\&C Technical Discipline Team (TDT)", C. J. Dennehy, AIAA-2010-829395. AIAA GN\&C Conference, Toronto, Ontario, Canada, 5 August 2010 